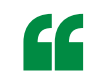

The fastreleasing pool of immature calyces from MUNC131 W464R mice

was much

slower to recover from depletion compared with wild-type mice

\title{
Short-term consequences for calyces
}

Short-term synaptic depression (STD) is a type of plasticity that occurs at many synapses in response to highfrequency stimulation (HFS). STD is mainly caused by depletion of the readily releasable pool (RRP) of synaptic vesicles. The recovery from STD is controlled by the $\mathrm{Ca}^{2+} /$ calmodulindependent replenishment of the RRP, but the mechanism by which this occurs is not known. A new study by Lipstein et al. shows that an interaction between $\mathrm{Ca}^{2+} /$ calmodulin and the vesicle priming protein MUNC13-1 (also known as UNC13A) has a crucial role.

A key stage of replenishment of the $\mathrm{RRP}$ is vesicle priming, and at calyx of Held synapses, this involves the $\mathrm{Ca}^{2+}$-dependent active zone protein MUNC13-1. Early in postnatal development, calyx synapses undergo maturation, which improves their processing speed and reliability, and the authors sought to determine the involvement of MUNC13-1 in RRP replenishment in both immature and mature calyx synapses. They generated a knockin mouse that expressed a variant of MUNC13-1 in which $\mathrm{Ca}^{2+}$-dependent binding to $\mathrm{Ca}^{2+} /$ calmodulin was disrupted (MUNC13-1 ${ }^{\mathrm{W} 464 \mathrm{R}}$ mice). Patch-clamp recordings of calyx of Held synapses in brainstem slices enabled estimation of the rate of RRP recovery using a paired-pulse protocol.

It is known that vesicle release from the RRP of calyces consists of two phases - a fast component and a slow component, reflecting fast- and slow-releasing pools of vesicles.

The fast-releasing pool of immature

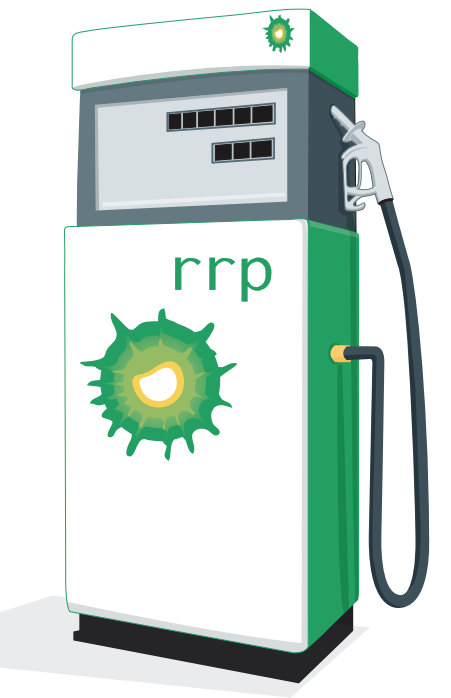

J. Vallis/NPG calyces from MUNC13-1 ${ }^{\mathrm{W} 464 \mathrm{R}}$ mice was much slower to recover from depletion compared with wild-type mice, whereas recovery time of the slow-releasing pool was the same in both groups. At mature calyces, both the fast- and slow-releasing vesicle pools of MUNC13-1 ${ }^{\mathrm{W} 464 \mathrm{R}}$ mice were affected. In addition, recovery of the fast-releasing pool in wild-type mice (both immature and mature) was reduced by exposure to an inhibitor of calmodulin, further implicating $\mathrm{Ca}^{2+} /$ calmodulin and MUNC13-1 signalling in RRP recovery. Finally, the authors found that disruption of the interaction between $\mathrm{Ca}^{2+} /$ calmodulin and MUNC13-1 in MUNC13-1 ${ }^{\text {W464R }}$ mice resulted in aberrant STD.

These findings demonstrate, in an intact preparation, the importance of $\mathrm{Ca}^{2+} /$ calmodulin-MUNC13-1 signalling for RRP replenishment and for STD at calyx synapses throughout development.

Sian Lewis

ORIGINAL RESEARCH PAPER Lipstein, N. et al. Dynamic control of synaptic vesicle replenishment and short-term plasticity by Ca2+-Calmodulin-

Munc13-1 signaling. Neuron http://dx.doi. org/10.1016/j.neuron.2013.05.011 (2013) 